\title{
Fuzzy Logic Modeling Software for Educational Paths Data Analysis
}

\author{
Alexander A. Tarasyev ${ }^{1, \text { a) }}$, Camilo A. Ospina Acosta ${ }^{2, \text { b) }}$, Gavriil A. Agarkov ${ }^{1, \mathrm{c})}$ \\ ${ }^{1}$ Ural Federal University, 620002, Mira Street, 19, Ekaterinburg, Russia \\ ${ }^{2}$ Aclate, TX 78701, 401 Congress Avenue, Suite 2650, Austin, USA \\ a)Corresponding author: alextarassiev@mail.ru \\ b)camilo.ospinaa@gmail.com \\ c)g.a.agarkov@urfu.ru
}

\begin{abstract}
Recent trends in the global education system are leading to the increasing competition in the field of higher education, which represent a big challenge for the universities participating in major rankings such as QS and THE. To improve the efficiency of the University, it is necessary to adjust its educational trajectories and programs in such a way as to meet the expectations of the student and the needs of the labor market. To describe the individual choice of the educational path, we used an econometric model, which takes into account the economic motivation of a potential student. Based on this model, we made a reasonable forecast of the future professional choice of students and their future income. After evaluating the amount of possible alternative educational paths for students, we made an estimation of the probability of a student changing of educational path using fuzzy logic model of Mamdani type. According to this approach, the probability of changing the educational trajectory for the student is calculated based on panel data, taking into account the amount of possible directions of graduation and educational paths of the student, the possibility of budgetary support of the graduation and the expected level of wages after graduation. To estimate the probability we developed a set of rules of the fuzzy inference system, designed to simulate the human behavior of making the decision of change between one and another educational path. The proposed architecture of the educational process analysis system (EPAS) provides educational institutions with the opportunity to establish business rules in accordance with their own needs. Based on this model, it is possible to analyze the impact of students' choice on the economic sectors development.
\end{abstract}

Keywords: modelling theory, fuzzy logic, optimization methods, mathematical economic modeling, systems behavior, higher education system, educational paths, behavioral economics, economic expectancies.

\section{INTRODUCTION}

Global trends in the education system are leading to the increasing competition in the field of higher education. Optimal use of University resources in conditions of high competition for students requires a comprehensive analysis of motivational factors of the student, as well as analysis of financial, educational and scientific efficiency of the University. To solve the problem of optimizing the educational process, depending on the demand in the labor market and personal expectations of the student, we focus on describing and predicting the individual behavior of potential students and modeling its impact on the development of the University. The choice of a university and an educational path determines student's current and future personal well-being. At the same time, the choice of an educational path, made by each student, impacts on the further development of economic sectors. In this article, we analyze student's economic motivation in the context of individual behavior theory. The choice of an educational path depends on a set of economic factors, such as tuition fees, available scholarships, and the expected income after graduation. It is necessary to highlight, that the question of education recoupment for students is very important. To estimate the amount of possible educational paths for each student we use an econometric model of optimization, based on the theory of human economic behavior and the methodology of increasing efficiency of the human capital. This econometric model works in conjunction with a custom fuzzy modeling software, which allows

International Conference of Numerical Analysis and Applied Mathematics ICNAAM 2019

AIP Conf. Proc. 2293, 120005-1-120005-4; https://doi.org/10.1063/5.0027176

Published by AIP Publishing. 978-0-7354-4025-8/\$30.00 
validating the relationship between the established variables of the study and the decision of a student to choose or to change the educational path. To be able to create a fuzzy logic model, it first required to determine the variables, which are going to be of relevance for the model. This is possible by analyzing the results, obtained from the econometric model of optimal educational paths. Our work presents a look into the complexities and applications of fuzzy logic software, to be more specific about the implementation of software that makes use of fuzzy inference systems to analyze problems of nonlinear behavior.

\section{THEORETICAL FRAMEWORK}

According to the classical theory of individual economic behavior, student's decisions depend on the considerations of clear rationality. Behavioral economists assume that people react differently to equivalent situations depending on their own estimates, whether they lose or win. According to the classical theory of individual economic behavior, rational individuals take into account the considerations of clear rationality. Individuals choose the best way to maximize their benefits or look for a job with the best possible future salary. In terms of the theory of modern institutional economics, we assume that the limitations of the institutions largely determine the economic behavior of the individual [4].

Modern institutional theory of economics argues that the constraints imposed by institutions economic determine the behavior of an individual. The study of the Economics of higher education and, in particular, the economic analysis of preferences is an urgent task of researchers. Many researchers consider the analysis of the choice of profession as an important component of the described system. In their works, researchers consider the dependence of the expected income after graduation from various specialties [3]. It is clear that the educational choices made by young people, depend on both the education system and public finance sector as a whole. At the same time, scientists consider various aspects, for example, awareness of students about the availability of concessional lending when obtaining a loan [2]. We wish to highlight that this influence has a significant national distinctiveness. Economists can trace the interdependence of the different characteristics of students and the financial implications of their higher education degrees $[1,7]$.

The results of the analysis indicate that non-monetary factors are the key aspects that determine the choice of specialty. Students with lower expected returns than their classmates are more likely to leave the University without a degree. Taking into account the advantages of an individual diploma of business education for international recruiters, some researchers oppose the method of financial interpretation of the costs and benefits of business education to a holistic approach based on the concepts of "internal" and "external" career success. At the same time, they shift the focus towards a precedence of social values. In our study, we use the classical economic approach. We conducted training on the decision-making model in three stages with an emphasis on the importance of choosing educational trajectories taking into account the expected income. The state of the Russian higher education provides extensive statistic data to analyze the impact of economic incentives on human behavior.

\section{EDUCATIONAL PATHS ESTIMATION}

To construct an econometric model of optimization of higher education, we analysed a dataset describing the educational trajectories of 10,954 students, and described their behavior by an optimization function. To establish an agent-based approach we need to group these students according to their main personal characteristics [5]. Therefore we denote the student's Unified State Examination (the USE) marks, submitted to the university selection committee, as $e_{s}$, where $s \in \overline{1, m}$. Here the parameter $m$ denotes the numbers of required exams at the matrix $Q$. Matrix $Q$ describes the set of exams, required for the chosen specialities. In the case, when the exams are not required, we denote $e_{s}$ equal to zero, $s \in \overline{1, m}$. The enrolment marks, corresponding to the chosen speciality $k \in \overline{1, l}$, are determined by parameter $o v_{k}$ for the paid tuition, and, by the parameter $o b_{k}$, for the budgeted tuition, where $o b_{k}<$ $o v_{k}$. Here the parameter $l$ denotes the number of specialities for the final $Q$. Coefficients $q_{k s}$ of the matrix $Q$, describing the initial agent's behavior, are given according to the following rule: $q_{k s}=1$ if examination $s$ is necessary for speciality $k ; q_{k s}=0$ if the examination $s$ is not required for the speciality $k$.

The parameter $c_{k}$ denotes a tuition fee for the speciality $k$, considering the overall cost for the whole education period. The parameter $c v_{k}$ stands for student's education costs in speciality $k$ : $c v_{k}=0$ if a student's educational path allows you to use budget funds, and $c v_{k}=c_{k}$, if tuition requires payment, $k \in \overline{1, l}$. The parameter $w_{k}$ means the 
expected income of a student over the two-year working period, following the graduation. This allows simulating the agent's economic behavior, taking into account the amount of tuition fees and expected salary after graduation.

We analyze the costs of a student's education process. In these conditions we need to maximize the gap $y_{k}(t)$ between the expected student's salary level after the graduation and the education costs for each academic year. According to the main idea of this approach, we compare the available personal skills with the current ones in the general average group of students. At the same time, we must consider the following conditions and determine the potential of higher education budget resources:

$$
\begin{aligned}
& \sum_{s=1}^{m} e_{s} \cdot q_{k s} \leq o b_{k} \Rightarrow c v_{k}=0 \\
& \sum_{s=1}^{m} e_{s} \cdot q_{k s} \leq o b_{k} \Rightarrow c v_{k}=c_{k}
\end{aligned}
$$

Here $q_{k s}$ are coefficients of the matrix $Q ; k \in \overline{1, l}$ and $s \in \overline{1, m}$. As the result, we see the possibility of free costs for the student's education process and estimate possible alternative educational paths for each student during the period of education. At the final stage of this model we get a matrix $Y=\left(x_{r k}\right)_{X \times K}$, which describes the amount of students $r=1, \ldots, X$, graduated each specialty $k=1, \ldots, K$.

The relationship of the main variables depends on some rules defined by expert knowledge, as mentioned earlier, as they represent nonlinear behavior and require an analysis of human behavior to establish the way in which a person decides to follow a new path when given the right opportunity. In this way, we implement a Mamdani Fuzzy Model to represent the relation between the variables (Fig. 1).

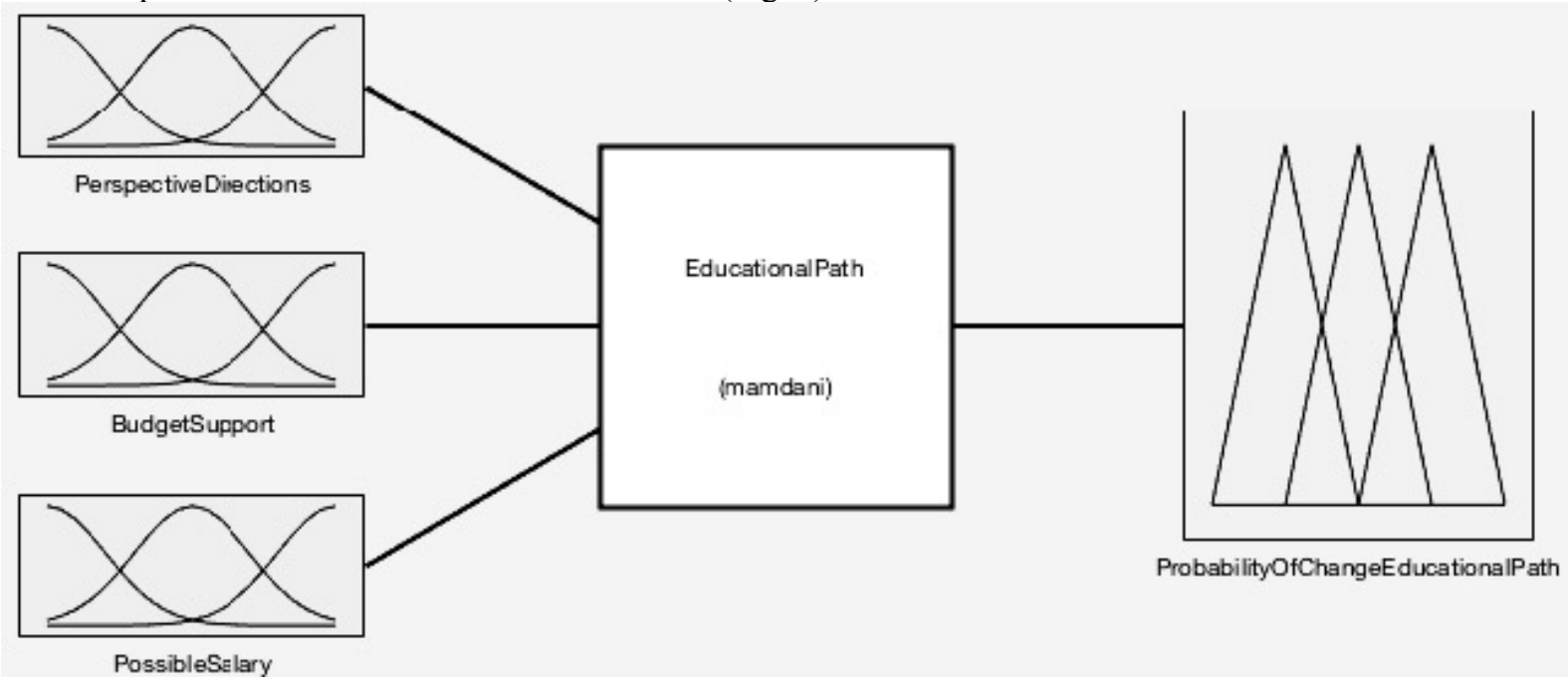

FIGURE 1. Mamdani Fuzzy Model for Educational Path Change.

\section{SOFTWARE DEVELOPMENT}

As a rule, the software system has a specific purpose, but for the tool used in a wide range of analysis and modeling tasks, it is necessary to have the ability to adapt quickly [6]. The first step in the process of development, after analyzing the requirements is to choose the tools and environment to develop the software. Figure 2 shows a deeper look at how the core module works in the application architecture layer. The Educational Processes Analysis System (EPAS) depends on the use of one or more fuzzy inference systems that enable the system to accept large amounts of data stored in the data layer.

The shown architecture intends to solve all the problems stated by the requirements. To do so two core elements are the base of the software: The first one is a custom wrapper for the JFuzzyLite Java library that has the purpose of simplifying working with the third-party library, and also to add new functionalities and methods that are required to make models in an easier and controlled way. The second core element is the use of a framework for web interfaces called Vaadin, which focuses on simplicity. This framework provides the look and feel of all the elements that the software will use and allows to put the developing effort in the layout of the components rather than the actual HTML, CSS's, and JavaScript. 


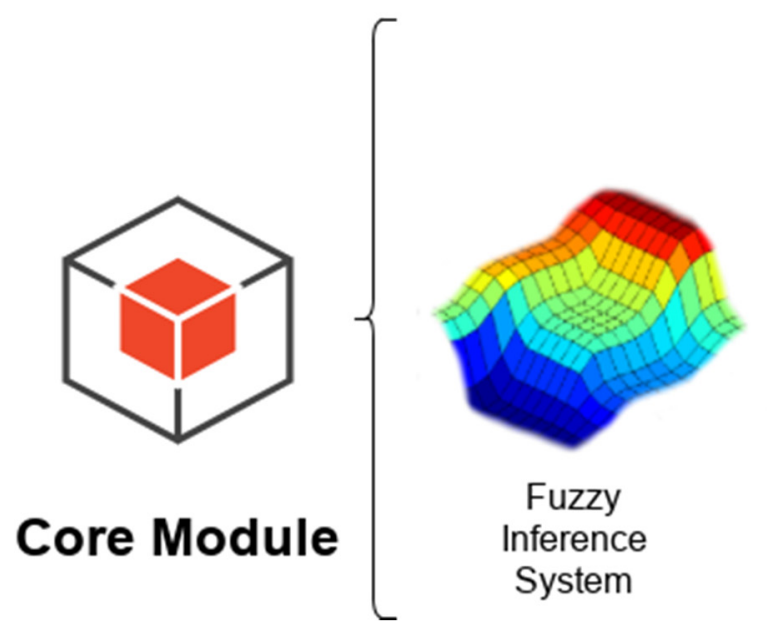

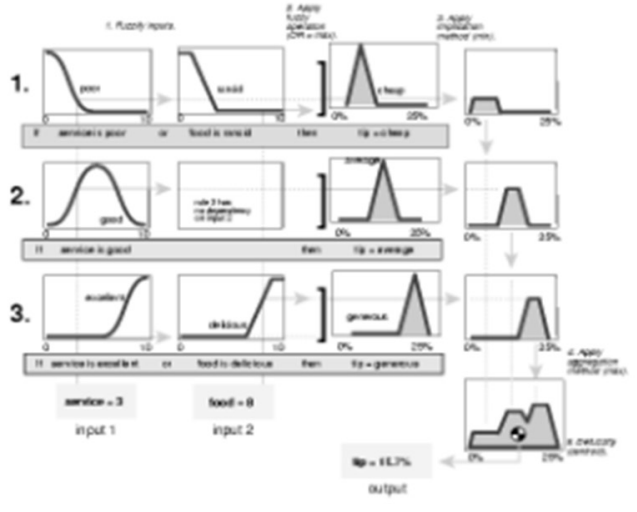

Rules of the System

FIGURE 2. Structure of the Educational Processes Analysis System EPAS.

\section{CONCLUSION}

The use of software for modeling fuzzy logic and the creation of a user model allowed us to describe the probability of changes in educational paths. At the same time, based on this model, it was possible to analyse the impact of students' choice on the economic sectors development. The probability of changing the educational path in the current model varies between five levels and depends on the number of promising areas of study of students, the possibility of budgetary support for each student and the expected level of wages after graduation.

For the further research, we plan to extend the model by analyzing individual's social and personal characteristics. New elements at the extended model have to include personal characteristics, such as gender, age, progress in research and indirect assessment of personal qualities. We plan to select these characteristics using big data analysis methods. It is necessary to expand the possibilities of model analysis, adding the aftereffect of the selected educational trajectories and cluster analysis of possible educational paths. With this approach, it is possible to assess the probability of changes in the educational path for each student and optimize the learning process at the University. The combination of fuzzy logic models, optimization models and search \& matching models will make it possible to adjust the educational process depending on the demand in the labor market.

\section{ACKNOWLEDGEMENTS}

The work was supported by Act 211 Government of the Russian Federation, contract № 02.A03.21.0006.

\section{REFERENCES}

[1] Bachan R. (2014). Students' expectations of debt in UK higher education. Studies in Higher Education. Vol. 39. 5. pp. 848-873.

[2] Booij A.S., Leuven E. \& Oosterbeek H. (2012). The role of information in the take-up of student loans. Economics of Education Review. 31 (1). pp. 33-44.

[3] Carnoy M., Froumin I., Loyalka P.K. \& Tilak J.B.G. (2014). The concept of public goods, the state, and higher education finance: a view from the BRICs. Higher Education. pp. 1-20.

[4] Geoffrey M. Hodgson (2003). The hidden persuaders: institutions and individuals in economic theory. Cambridge Journal of Economics. pp. 159-175.

[5] Koksharov, V.A., Agarkov, G.A. (2015). Analysis of economic motivation when individuals choose an educational path. Economy of Region. Vol. 1. pp. 245-252.

[6] Thukral R. and Goel A. (2015). Framework for Web Services in Education Management. International Conference on Information Technology (ICIT). pp. 215-220.

[7] Alexandr A. Tarasyev, Gavriil Agarkov, Aleksandr Medvedev (2017). Optimization of Educational Paths for Higher Education, AIP Conference Proceedings 1906, p. 070008. 